\title{
Thymine DNA Glycosylase (TDG) is involved in the pathogenesis of intestinal tumors with reduced $A P C$ expression
}

\author{
Jinfei $\mathrm{Xu}^{1,{ }^{1}}$, Salvatore Cortellino ${ }^{1, *}$, Rossella Tricarico ${ }^{1}$, Wen-Chi Chang ${ }^{2}$, Gabrielle \\ Scher $^{1}$, Karthik Devarajan ${ }^{3}$, Michael Slifker ${ }^{3}$, Robert Moore ${ }^{1}$, Maria Rosaria Bassi ${ }^{1}$, \\ Elena Caretti ${ }^{1}$, Margie Clapper ${ }^{2}$, Harry Cooper ${ }^{4}$ and Alfonso Bellacosa ${ }^{1}$ \\ ${ }^{1}$ Cancer Epigenetics Program, Fox Chase Cancer Center, Philadelphia, PA 19111, USA \\ ${ }^{2}$ Cancer Prevention and Control Program, Fox Chase Cancer Center, Philadelphia, PA 19111, USA \\ ${ }^{3}$ Department of Biostatistics, Fox Chase Cancer Center, Philadelphia, PA 19111, USA \\ ${ }^{4}$ Department of Pathology, Fox Chase Cancer Center, Philadelphia, PA 19111, USA \\ *These authors have contributed equally to this work \\ Correspondence to: Alfonso Bellacosa, email: Alfonso.Bellacosa@fccc.edu \\ Keywords: TDG, APC, colorectal cancer, intestinal cancer \\ Received: July 17, $2017 \quad$ Accepted: August 21, 2017 \\ Published: September 23, 2017 \\ Copyright: $\mathrm{Xu}$ et al. This is an open-access article distributed under the terms of the Creative Commons Attribution License 3.0 \\ (CC BY 3.0), which permits unrestricted use, distribution, and reproduction in any medium, provided the original author and source \\ are credited.
}

\section{ABSTRACT}

Thymine DNA Glycosylase (TDG) is a base excision repair enzyme that acts as a thymine and uracil DNA N-glycosylase on G:T and G:U mismatches, thus protecting CpG sites in the genome from mutagenesis by deamination. In addition, TDG has an epigenomic function by removing the novel cytosine derivatives $\mathbf{5}$-formylcytosine and 5-carboxylcytosine (5caC) generated by Ten-Eleven Translocation (TET) enzymes during active DNA demethylation. We and others previously reported that TDG is essential for mammalian development. However, its involvement in tumor formation is unknown. To study the role of TDG in tumorigenesis, we analyzed the effects of its

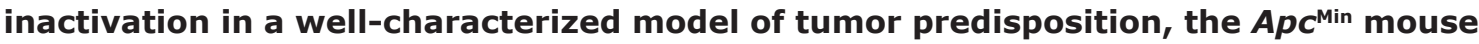
strain. Mice bearing a conditional Tdg $^{\text {flox }}$ allele were crossed with Fabpl::Cre transgenic mice, in the context of the $A_{p c^{\text {Min }}}$ mutation, in order to inactivate $T d g$ in the small intestinal and colonic epithelium. We observed an approximately 2 -fold increase in the number of small intestinal adenomas in the test $\boldsymbol{T d g}$-mutant $\boldsymbol{A p c}^{\mathrm{Min}}$ mice in comparison to control genotypes $(p=0.0001)$. This increase occurred in female mice, and is similar to the known increase in intestinal adenoma formation due to oophorectomy. In the human colorectal cancer (CRC) TCGA database, the subset of patients with TDG and $A P C$ expression in the lowest quartile exhibits an excess of female cases. We conclude that TDG inactivation plays a role in intestinal tumorigenesis initiated by mutation/ underexpression of APC. Our results also indicate that TDG may be involved in sexspecific protection from CRC.

\section{INTRODUCTION}

Cytosine and 5-methylcytosine $(5 \mathrm{mC})$ are intrinsically unstable in genomic DNA and have a tendency to spontaneously deaminate, generating thymine and uracil, respectively, which, if not removed from the G:T and G:U mismatches prior to replication, will lead to incorporation of adenine $[1,2] .5 \mathrm{mC}$ is mostly located at palindromic $\mathrm{CpG}$ sequences, and this mechanism of $\mathrm{CpG}$ site mutagenesis by deamination is estimated to cause nearly one-third of all mutations in both cancer and human genetic diseases $[3,4]$. In particular, through recent next-generation sequencing, transition mutations at $\mathrm{NpCpG}$ sites are being recognized as the most frequent 
mutational signature across the vast majority of cancer types [5]. In order to maintain genomic stability at $\mathrm{CpG}$ sites, two base excision repair enzymes, Thymine DNA Glycosylase (TDG) and Methyl-Binding Domain 4 (MBD4), remove the offending thymine and uracil with their DNA $N$-glycosylase activity [6-9].

In addition to its role in genomic stability of $\mathrm{CpG}$ sites, TDG is also required for active DNA demethylation during development; TDG balances the activity of DNA methyltransferases by maintaining $\mathrm{CpG}$ islands in their unmethylated state and promoting demethylation of tissuespecific, developmentally regulated enhancers $[10,11]$. In this role in epigenomic stability, TDG acts downstream the Ten-Eleven Translocation (TET) family of dioxygenases in pathways of DNA demethylation initiated by iterative oxidation of $5 \mathrm{mC}$ to the novel cytosine species: 5-hydroxymethylcytosine ( $5 \mathrm{hmC}), 5$-formylcytosine ( $5 \mathrm{fC})$ and 5-carboxylxytosine $(5 \mathrm{caC})$. In fact, TDG is the main biochemical activity involved in removal of $5 \mathrm{fC}$ and $5 \mathrm{caC}$ $[9,12]$. It should be noted that a similar role of MBD4 in DNA demethylation has been proposed but remains controversial; in fact, whereas TDG is essential [10, 13], MBD4 is dispensable for mammalian development [9].

Mutagenesis by deamination is thought to play an important role in human colorectal cancer (CRC); CRC has a high frequency of mutations at $\mathrm{NpCpG}$ sequences (so-called signature 1 mutations), and half of TP53 inactivating mutations, which are critical alterations for CRC progression [14], are G:C to A:T transitions within a CpG site [5, 15-17]. In addition, altered methylation patterns (epimutations) are known to be involved in the pathogenesis of CRC with genome-wide hypomethylation and hypermethylation and silencing of $\mathrm{CpG}-$ rich sequences ( $\mathrm{CpG}$ islands) at promoters of tumor suppressor and other genes $[18,19]$. Thus, MBD4 and/or TDG defects may contribute to $\mathrm{CRC}$ formation.

Indeed, we and others have shown that MBD4 is frequently mutated in microsatellite unstable, mismatch repair (MMR)-defective CRC [20-22]; and affects the mutational landscape independent of the MMR defect [23]. Moreover, enhanced tumorigenicity due to MBD4 inactivation could be demonstrated by breeding Mbd4 mutant mice with the $A p c^{\text {Min }}$ mouse [24, 25], which is a very sensitive reporter system to score genetic interactions with the $A p c$ tumor suppressor gene [26, 27]. However, despite its presumed role in genomic and epigenomic instability, the involvement of TDG in cancer, and in particular in CRC, is poorly characterized, with the exception of a study in which $T D G$ inactivation in a rectal carcinoma from a patient with constitutional MMR deficiency increased the number of $\mathrm{C}>\mathrm{T}$ transitions at CpG sites [28]. In this article, we conducted human and mouse studies, which concordantly establish a role for inactivation of $T D G$, as an important tumor suppressor in the pathogenesis of a subset of intestinal tumors.

\section{RESULTS}

\section{Generation of mice bearing a conditional $\boldsymbol{T d} g$ knock-out allele and intestinal inactivation of $T d g$ in the context of the $A p c^{\text {Min }}$ mutation}

To study the role of TDG in intestinal tumor formation, we conditionally inactivated $T d g$ in the small intestine and colon. Tissue-specific conditional inactivation was necessary in order to bypass embryonic lethality associated with $T d g$ inactivation in the germline $[10,13]$. We previously described the generation of mice bearing the inactive, null allele $T d g$, in which Cremediated recombination between the loxP sites generates a deletion of exons 3 through 7 [10]. Mice with the conditional $T d g$ allele ( $\left.T d g^{\text {flox }}\right)$, were generated by crossing mice bearing the original recombined locus ( $\left.T d g^{\text {neoflox }}\right)$ with mice expressing the enhanced Flp recombinase at the Rosa26 locus (Rosa26::FlpeR) [29]. Through this cross, Flp-mediated recombination of the frt sites excises the neo gene, generating a $T d g^{\text {flox }}$ allele with $\operatorname{lox} P$ sites flanking exons 3 and 7 (Supplementary Figure 1). Mice homozygous for the $T d g^{\text {flox }}$ allele do not exhibit lethality or infertility, and age normally (data not shown), thus confirming that this allele is indeed conditional.

Finally, mice bearing the conditional $T d g^{\text {flox }}$ allele were crossed with Fabpl::Cre transgenic mice, which yields mosaic gene inactivation in the small intestine and colon [30, 31], and with the Fox Chase Cancer Center strain of $A p c^{\mathrm{Min}}$ mice, $A p c^{\mathrm{Min}-\mathrm{FCCC}}$ [32]. All the mice were maintained on a nearly pure C57/BL6 background (see Material and Methods for details).

\section{Increased adenoma formation in $\mathrm{Fabpl}:: \mathrm{Cre}^{+/ \mathrm{o}}$ $\boldsymbol{T d g}^{\mathrm{flox} /-} \boldsymbol{A p c}^{\mathrm{Min} /+}$ mice}

A total of 67 mice were divided into four groups; the test cohort with genotype Fabpl:: $\mathrm{Cre}^{+/ \mathrm{o}} \mathrm{Tdg}^{\mathrm{flox} /-} A p c^{\mathrm{Min} /+}$, and the control cohorts with genotypes Fabpl::Cre $\mathrm{Cro}^{+/ o} \mathrm{Tdg}^{+/-}$ Apc $^{\mathrm{Min} /+}$, Fabpl: $: \mathrm{Cre}^{+/ \mathrm{o}} \mathrm{Tdg}^{+/ \text {flox }}$ Apc $^{\mathrm{Min} /+}$ and Fabpl $: \mathrm{Cre}^{+/ \mathrm{o}}$ $\mathrm{Tdg}^{+/+} A p c^{\mathrm{Min} /+}$. Mice were aged and sacrificed at 150 days, as done in previous studies of the Fox Chase Cancer Center strain of the $A p c^{\text {Min }}$ mouse [32], and the total number of gross and microscopic adenomas was counted. The results revealed that the test $T d g^{\text {flox/- }}$ mice exhibit an approximately two-fold increase in the number of small intestinal adenomas in comparison to control genotypes $(p=0.0001)$ (Figure 1A). No difference was seen in the number of caecum and colonic adenomas (Figure 1A). No carcinomas were seen.

To evaluate whether $T d g$ deletion alters the mechanism of inactivation of the second (normal) copy of the $A p c$ gene in adenomas, a total of 4 matched normal

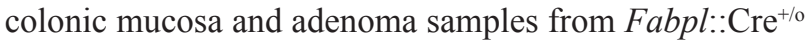
$T d g^{\text {flox/- }} A p c^{\mathrm{Min} /+}$ mice were analyzed for $A p c$ loss of 
heterozygosity by pyrosequencing around the $A p c^{\text {Min }}$ mutation. We found that all the adenomas tested exhibited loss of heterozygosity (Figure 1B), as in the classical model of intestinal tumorigenesis in $A p c^{\mathrm{Min} /+}$ mice [33].

Pathological examination of small intestinal adenomas from the test $\mathrm{Fabpl}:: \mathrm{Cre}^{+/ \mathrm{o}} \mathrm{Tdg}^{\text {flox/- }} A p c^{\mathrm{Min} /+}$ mice in comparison to adenomas from control $\mathrm{Fabpl}:: \mathrm{Cre}^{+/ \mathrm{o}}$ $\mathrm{Tdg}^{+/+} A p c^{\mathrm{Min} /+}$ mice revealed an excess of poorly differentiated tumors, in which the differentiated gland (crypt/villus) architecture had been lost (Figure 2). Specifically, 16/44 (36.4\%) adenomas examined displayed undifferentiated features in Fabpl:: $\mathrm{Cre}^{+/ \mathrm{o}} \mathrm{Tdg}^{\mathrm{flox} /-} \mathrm{Apc}^{\mathrm{Min} /+}$ mice vs. 8/74 (10.8\%) in Fabpl:: $\mathrm{Cre}^{+/ o} \mathrm{Tdg}^{+/+} A p c^{\mathrm{Min} /+}$ mice $(p=0.0017$, Fisher's exact test). In addition, adenomas in Tdg-mutant mice were characterized by vesicular nuclei with prominent nucleoli and infiltration of eosinophils (Figure 2B, 2D). This histology indicates a possible role for TDG in the establishment or maintenance of the differentiated state of the small intestine.

\section{The increased adenoma number in Fabpl:: $\mathrm{Cre}^{+/ \mathrm{o}}$}

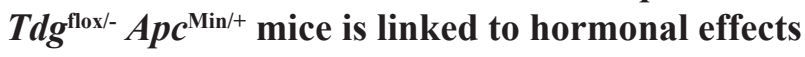

When we divided the test and control mice by sex, we noticed that the increased adenoma formation associated with the Fabpl::Cre $\mathrm{Cd}^{+/ o} \mathrm{Td}^{\mathrm{flox} /-} A p c^{\mathrm{Min} /+}$ genotype was more prevalent in female mice (Table 1), indicating an involvement of sex hormones in the mechanism of action of $T d g$ inactivation. Since TDG is a known co-activator of estrogen receptor (ER) $\alpha$ [34] and $\beta$ [35], and ovariectomy increases adenoma formation in $A p c^{\mathrm{Min}}$ mice [36], it is possible that the known protective effect of female hormones, and especially estrogens, on CRC formation [37] is TDG-dependent. To test this possibility, female mice of the test Fabpl: $\mathrm{Cre}^{+/ o} \mathrm{Tdg}$ flox$A p c^{\mathrm{Min} /+}$ genotype and the three control genotypes underwent ovariectomy at 5-6 weeks and were scored for intestinal adenoma formation at 150 days (Table 2). Importantly, a similar increased number of adenomas
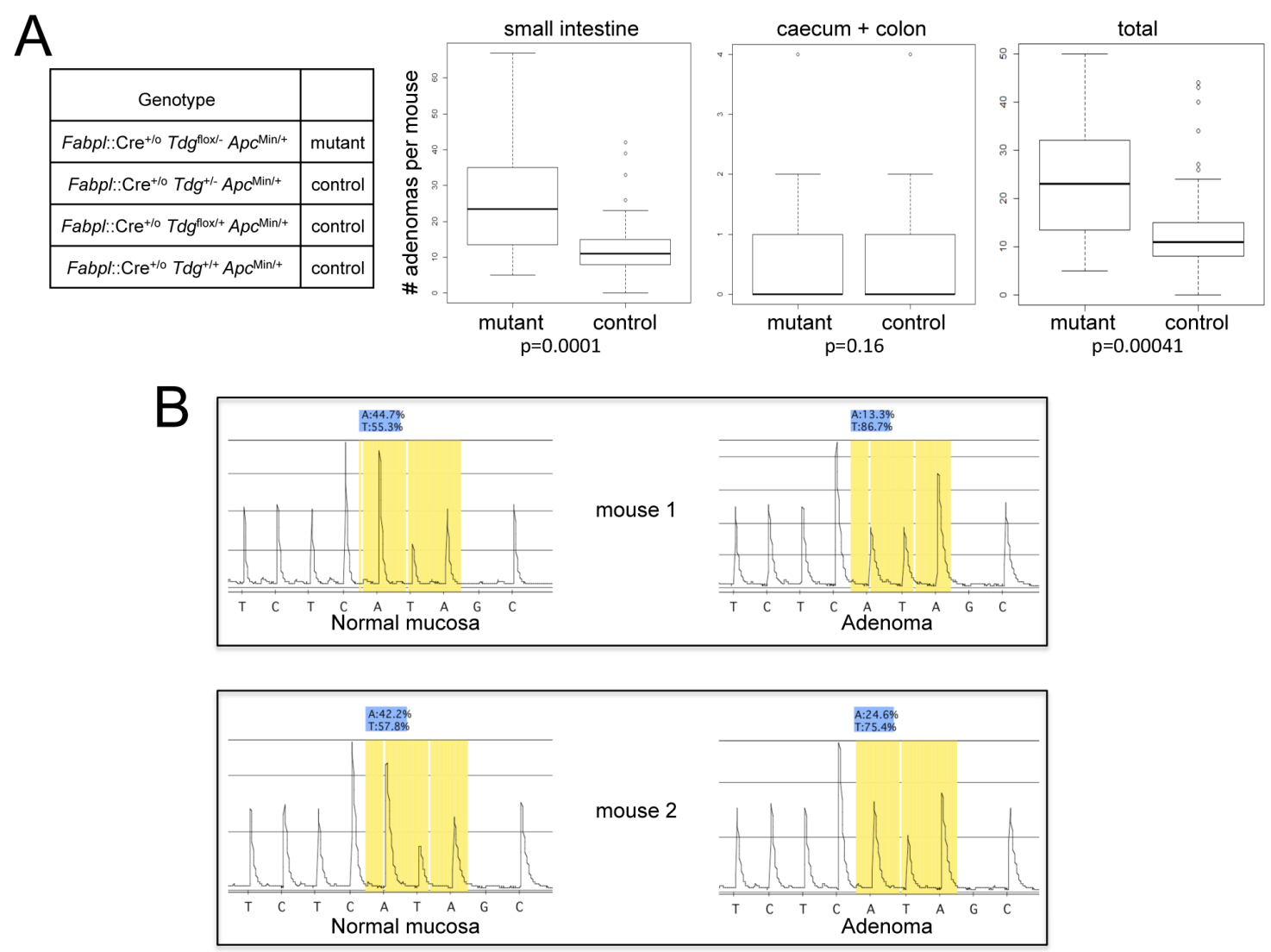

Figure 1: Increased intestinal tumor formation in $T d g$ conditional knock-out mice crossed into the $A_{p c} c^{\text {Min }}$ background. (A) Box plot representation of the distributional characteristics of the number of small intestinal, caecum plus colonic, and total adenomas

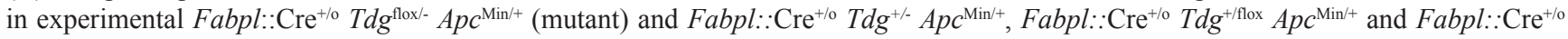
$\mathrm{Tdg}^{+/+} A p c^{\mathrm{Min} /+}$ (control) mice; the line in the box represents the median. The $p$ value was determined by two-sided Mann-Whitney test. The average tumor numbers and standard deviations are as follows: small intestinal, mutant: mean=26, $\mathrm{SD}=15.68$; small intestinal, control: mean=12.76, $\mathrm{SD}=8.95$; colon, mutant: mean $=0.84, \mathrm{SD}=1.26$; colon, control: mean $=0.41, \mathrm{SD}=0.74$; total, mutant: mean=23.84, $\mathrm{SD}=12.70$; total, control: mean=13.16, $\mathrm{SD}=9.35$. (B) Pyrogram of the complementary sequence around the $A p c^{\mathrm{Min}}$ mutation showing evidence of loss of heterozygosity in two adenomas from Fabpl:: $\mathrm{Cre}^{+/ \mathrm{o}} \mathrm{Tdg}^{\mathrm{flox} /-} A p c^{\mathrm{Min} /+}$ mice in comparison to normal mucosa. The $A p c^{\mathrm{Min}}$ mutation, a $\mathrm{T} \rightarrow \mathrm{A}$ point mutation at base 2,549, is present in heterozygosity (approximately 50\%) in normal mucosa of $\mathrm{Fabpl}_{:} \mathrm{Cre}^{\mathrm{+o}} \mathrm{Tdg}^{\mathrm{flox} /-} \mathrm{Apc} \mathrm{Min} /+^{\mathrm{mice}}$, and increases to approximately $75-85 \%$ in adenomas. 
Table 1: Sex-dependent impact of $T d g$ conditional mutation on adenoma formation

\begin{tabular}{|c|c|c|c|c|c|c|}
\hline Genotype & $\begin{array}{c}\text { Female mice } \\
\text { sacrificed }\end{array}$ & $\begin{array}{l}\text { Total no. } \\
\text { of tumors }\end{array}$ & $\begin{array}{c}\text { Average no. } \\
\text { of tumors } \\
\text { per mouse }\end{array}$ & $\begin{array}{c}\text { Male } \\
\text { mice } \\
\text { sacrificed }\end{array}$ & $\begin{array}{c}\text { Total } \\
\text { no. of } \\
\text { tumors }\end{array}$ & $\begin{array}{c}\text { Average no. } \\
\text { of tumors } \\
\text { per mouse }\end{array}$ \\
\hline Fabpl:: $\mathrm{Cre}^{+/ o} T d g^{\text {flox/- }} A p c^{\mathrm{Min} /+}$ & 11 & 344 & 31.3 & 8 & 123 & 15.4 \\
\hline Fabpl:: $\mathrm{Cre}^{+/ o} \operatorname{Tdg}^{+/-} A p c^{\mathrm{Min} /+}$ & 8 & 96 & 12 & 10 & 107 & 10.7 \\
\hline Fabpl:: $\mathrm{Cre}^{+/ o} T d g^{\text {flox/+ }} A p c^{\mathrm{Min} /+}$ & 9 & 124 & 13.8 & 14 & 163 & 11.6 \\
\hline Fabpl:: $\mathrm{Cre}^{+/ o} \operatorname{Tdg}^{+/+} A p c^{\mathrm{Min} /+}$ & 7 & 90 & 12.9 & 9 & 105 & 11.7 \\
\hline
\end{tabular}

(in comparison to the average number of adenomas in control mice not undergoing ovariectomy, Table 1) was detected in both the test Fabpl::Cre ${ }^{+/ 0} \operatorname{Tdg}^{\text {flox/- }} A p c^{\mathrm{Min} /+}$ genotype group and the control genotype groups (Table 2 ), indicating that ovariectomy is, in a way, "epistatic" with the mutant $T d g$ genotype, i.e. the protective effect of female hormones on intestinal tumor formation may be largely TDG-dependent.

\section{Involvement of $T D G$ in human colorectal cancer}

To evaluate the role of $T D G$ in human CRC, we first examined the expression of TDG in CRC cell lines of the NCI-60 panel. Western blot analysis revealed that the levels of TDG varied from high to low in these cell lines (Supplementary Figure 2), indicating a complex role in CRC formation.
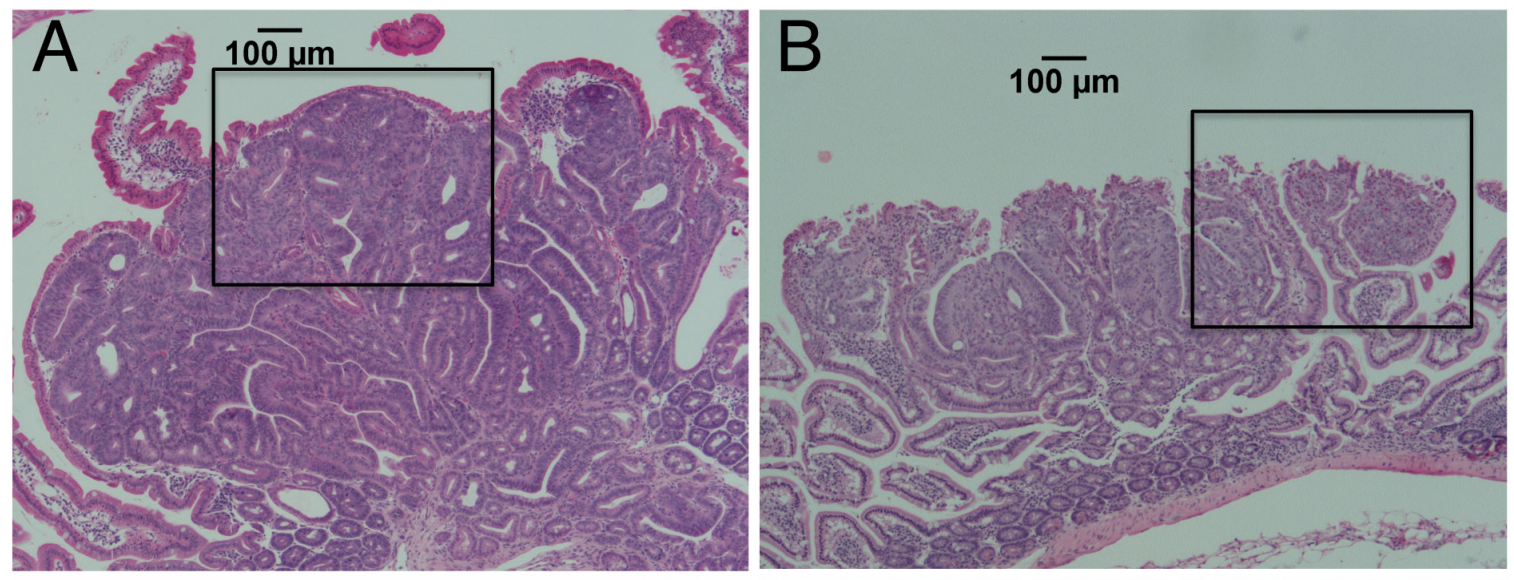

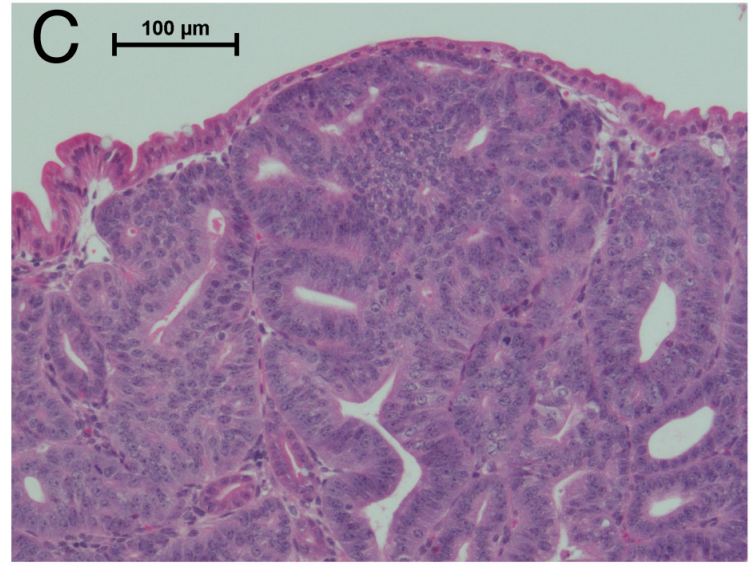

Fabpl::Cre $\mathrm{Cdg}^{+/+} \mathrm{Apc} \mathrm{Min/+}$

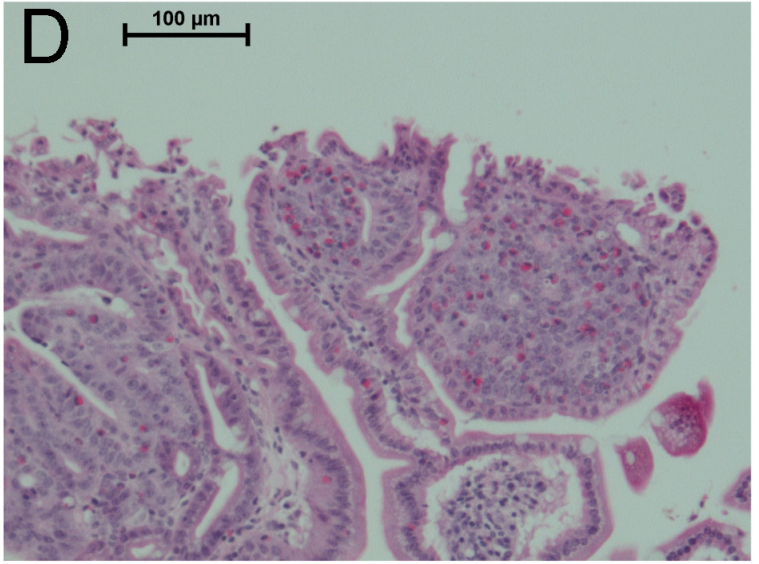

Fabpl::Cre ${ }^{+/ o} T_{d g}^{\text {flox/- }} A p c^{\mathrm{Min} /+}$

Figure 2: Histopathology of poorly differentiated small intestinal adenomas in Fabpl::Cre $^{+/ 0} \operatorname{Tdg}^{\text {flox/- }}$ Apc $^{\mathrm{Min} /+}$ mice. $^{-}$ Representative examples of morphological differences between typical well-differentiated adenomas in $\mathrm{Fabpl}_{:} \mathrm{Cre}^{+/ \mathrm{o}} \mathrm{Tdg}^{+/ /} \mathrm{Apc} \mathrm{Min}^{++}\left(\mathrm{Tdg}_{\mathrm{g}}\right.$ wild type) (A) and poorly differentiated adenomas in Fabpl::Cre ${ }^{+/ o} T d g^{\text {flox/- }} A p c^{\text {Min/+ }}$ mice ( $T d g$ conditional knock-out) (B). The respective insets (C and D) show an enlarged area. Poorly differentiated adenomas in Tdg conditional knock-out mice manifest vesicular nuclei with prominent nucleoli and infiltration of eosinophils. 
Table 2: Effect of ovariectomy on intestinal adenoma formation in $\boldsymbol{T d g}$ mutant and control mice

\begin{tabular}{|c|c|c|c|c|}
\hline Genotype & $\begin{array}{c}\text { Female mice } \\
\text { sacrificed }\end{array}$ & $\begin{array}{l}\text { Total no. of } \\
\text { tumors }\end{array}$ & $\begin{array}{l}\text { Average no. of } \\
\text { tumors per mouse }\end{array}$ & $\begin{array}{l}\text { Average no. of tumors } \\
\text { per female mouse } \\
\text { (from Table 1) }\end{array}$ \\
\hline Fabpl::Cre $\mathrm{Cr}^{+/ o} T d g^{\text {flox/- }} A p c^{\mathrm{Min} /+}$ & 13 & 359 & 27.6 & 31.3 \\
\hline Control mice (combined: & 7 & 166 & 23.7 & 12.9 \\
\hline \multicolumn{5}{|l|}{ Fabpl:: $\mathrm{Cre}^{+/ \mathrm{o}} \operatorname{Tdg}^{+/-} A p c^{\mathrm{Min} /+}$} \\
\hline \multicolumn{5}{|l|}{ Fabpl:: $\mathrm{Cre}^{+/ o} T d g^{\mathrm{flox} /+} A p c^{\mathrm{Min} /+}$} \\
\hline Fabpl:: $\left.\mathrm{Cre}^{+/ \mathrm{o}} \operatorname{Tdg}^{+/+} A p c^{\mathrm{Min} /+}\right)$ & & & & \\
\hline
\end{tabular}

Examination of the TCGA COAD (colon adenocarcinoma) and READ (rectal adenocarcinoma) data sets also revealed a wide range of TDG mRNA expression ratios between normal and tumor pairs in matched samples (Figure 3A-3C). Interestingly, we noticed a trend towards a correlation between low $T D G$ and low $A P C$ expression, which validates the relevance of our mouse model (Figure 3D, 3E).

Importantly, in 618 sporadic CRC samples processed on both RNA-Seq platforms (HiSeq \& GenomeAnalyzer), the cases with lowest quartile of expression for both $T D G$ and $A P C$ comprised a subset that is overrepresented by women $v s$. men (Table $3, \mathrm{p}=1.897 \mathrm{e}-05$ ), further validating the mouse model. Such overrepresentation was detected even when the analysis was limited to 372 CRC samples processed on the HiSeq platform only (Table 3, $\mathrm{p}=0.03333$ ). In keeping with the potential role of TDG in mediating the protective effects of estrogen, analysis of the TCGA data revealed a correlation between the lowest quartile of $T D G$ and $A P C$ expression, and low expression of the ER $\alpha$ gene (ESRl) (Figure 3F); the correlation with the ER $\beta$ gene (ESR2) was not significant (Figure $3 \mathrm{G}$ ).

In TCGA data, overall survival was not linked to the levels of $T D G$ expression (Supplementary Figure $3 \mathrm{~A}$ ), although the subset of patients with the high quartile of $T D G$ expression exhibited a trend towards increased overall survival in comparison to patients of the remaining three quartiles (Supplementary Figure 3B). Also, the subset of patients with $T D G$ and $A P C$ expression in the lowest quartile does not show different survival from all the other patients (Supplementary Figure 3C).

TDG has a prominent role in epigenomic regulation by acting downstream of the TET enzymes in DNA demethylation pathways [9]. Therefore, we wished to determine whether altered expression of $T D G$ relates to changes in DNA methylation in CRC. We mined the TCGA CRC DNA methylation data and correlated the expression levels of $T D G$ and, as controls, DNMT1 and $M B D 4$, to the beta values (methylation levels) for all the Infinium $450 \mathrm{~K} \mathrm{CpG}$ sites. The results revealed a distribution of correlations in which methylation levels at more sites are negatively correlated with $T D G$ expression than are positively correlated, as expected for the role of TDG in DNA demethylation (Figure 4). Conversely, DNMT1, acting as a positive control for this analysis, correlated mostly positively with methylation levels, in keeping with its enzymatic activity; $M B D 4$ did not show any preferential correlation (Figure 4). These results indicate that altered expression of $T D G$ has an impact on the degree of DNA methylation of CRC.

\section{DISCUSSION}

The combined results from our in vivo mouse studies and investigation of human cancer databases indicate a role of $T D G$ in the suppression of intestinal tumorigenesis, and particularly in sex-specific protection from CRC. In order to study the role of TDG in tumor formation, we generated mice bearing the conditional $T d g^{\text {flox }}$ allele to bypass embryonic lethality due to germ line inactivation, and took advantage of Fabpl::Cre transgenic mice for gene inactivation in the mouse intestine. To score unequivocally for a role of $T D G$ in intestinal tumor formation, we used the reliable model represented by the $A p c^{\mathrm{Min}}$ mice, which demonstrated a two-fold increase in the number of small intestinal adenomas in $T d g$ conditionally mutant mice in comparison to control mice.

Western blot analysis of a series of human CRC cell lines revealed a wide range of TDG expression levels. However, it has been reported that the expression levels of TDG are maintained, or even increased, in CRC samples in comparisons to normal colonic mucosa [38]. To resolve this apparent paradox, we analyzed the TCGA expression data and found that while the overall levels of TDG are maintained or increased in CRC, there exists a subset of cases characterized by reduced expression. Remarkably, this subset is also characterized by reduced $A P C$ expression, which lends functional significance to our model of mutant $T d g \times A p c^{\mathrm{Min}}$ mice.

An important uniformity of our mouse model and the human CRC subset is the sex bias. Both mutant Tdg $\mathrm{x} A p c^{\mathrm{Min}}$ mice and the low $T D G /$ low $A P C$ patient subset are characterized by an excess of female cases, which indicates that TDG may normally mediate the protective 
effects of estrogen on intestinal tumor formation. ER $\alpha$ and ER $\beta$ are known modifiers of APC-dependent tumorigenesis, and their inactivation increases intestinal tumor formation in the $A p c^{\text {Min }}$ mice [36, 39, 40]. Since TDG is a co-activator of $\operatorname{ER} \alpha$ [34] and $\operatorname{ER} \beta$ [35], it is possible that TDG participates to the protective effects of estrogen by fully promoting ER $\alpha$ - and ER $\beta$-mediated transcriptional activation.

Interestingly, adenomas in $T d g$ mutant mice show an excess of undifferentiated features in comparison to control mice, and a characteristic infiltration of eosinophils, which points to a possible role of $T d g$ in maintaining the proper
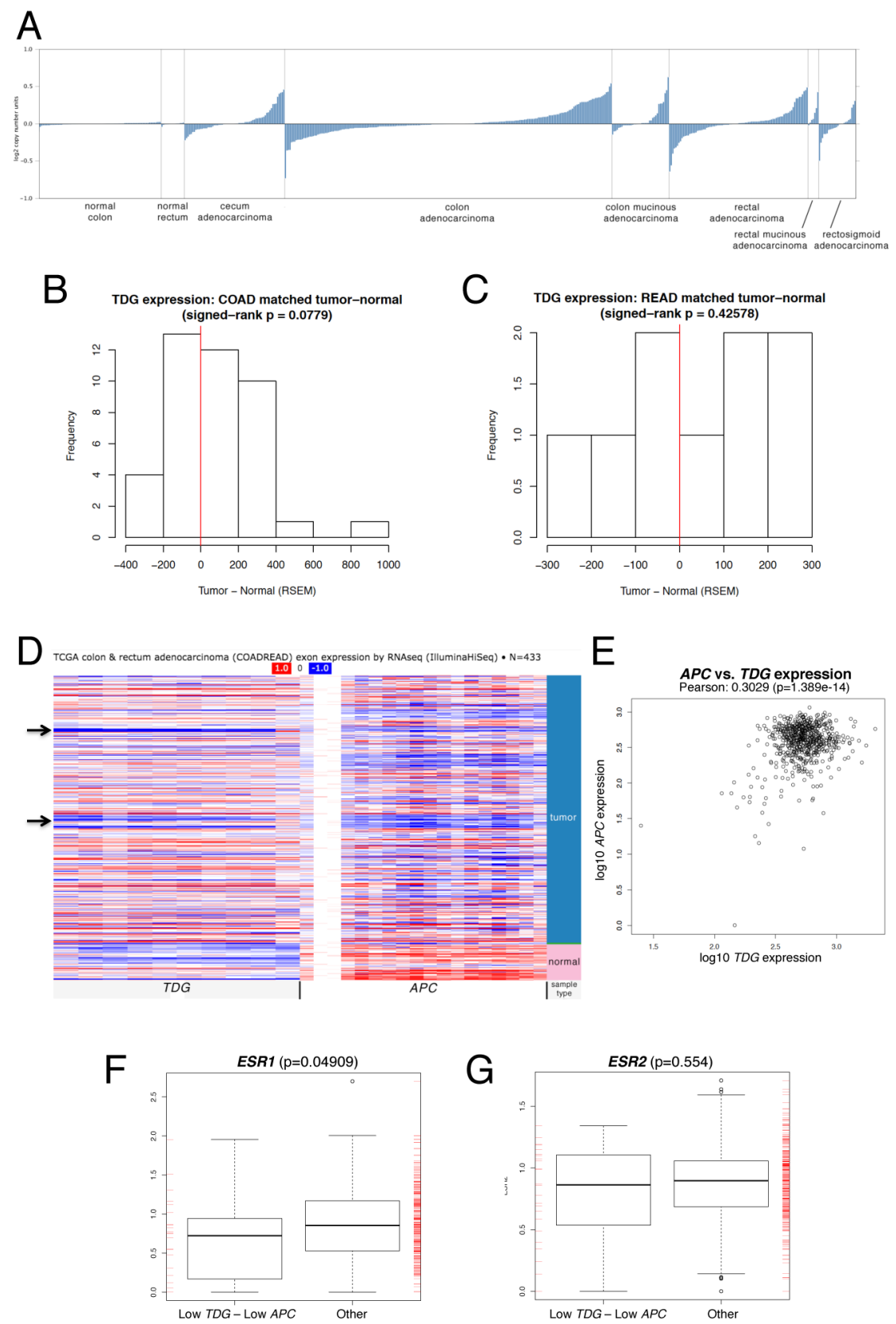

Figure 3: Relevance of $\boldsymbol{T D G}$ expression to human CRC. (A) Expression levels of TDG mRNA in normal colon and rectum, and corresponding adenocarcinomas (indicated) of the TCGA COAD (colon adenocarcinoma) and READ (rectal adenocarcinoma) data sets (Oncomine). Expression levels of TDG mRNA in matched normal-tumor samples of the TCGA COAD (colon adenocarcinoma) (B) and READ (rectal adenocarcinoma) (C) data sets. (D) Heatmap (UCSC Cancer Browser) showing expression of TDG and $A P C$ mRNA in normal and tumor samples from the TCGA COADREAD data sets. Arrows indicate group of tumors with reduced expression of both $T D G$ and $A P C$. (E) Pearson correlation of $T D G$ and $A P C$ mRNA expression levels in tumor samples from the TCGA COADREAD data sets. Box plot representation of the ESR1 (F) and ESR2 (G) mRNA expression levels in TCGA COADREAD samples with low quartile of both $T D G$ and $A P C$ expression $v s$. other samples. The $p$-value was determined by two-sided Mann-Whitney test. A significant difference was found for ESR1 but not ESR2. 
Table 3: Sex distribution of TCGA COADREAD tumors based on low quartile of TDG and $A P C$ expression

\begin{tabular}{lcccc}
\hline & \multicolumn{2}{c}{ HiSeq \& GenomeAnalyzer } & \multicolumn{2}{c}{ HiSeq only } \\
\hline Group & Female & Male & Female & Male \\
\hline Low TDG - Low APC & 39 & 13 & 16 & 8 \\
Other & 250 & 316 & 151 & 197 \\
$p$ value & & $1.897 \mathrm{e}-05$ & & 0.03333 \\
\hline
\end{tabular}

intestinal architecture and avoiding abnormal chemotactic stimuli. In addition, the solid, undifferentiated architecture and nuclear/nucleolar morphology is reminiscent of the histology of human CRC with the so-called $\mathrm{CpG}$ island methylator phenotype (CIMP) $(37,102)$, which raises the possibility that loss of TDG demethylating activities may promote the onset of tumors characterized by altered methylation. A potential confirmation of this contention is the fact that in the TCGA CRC dataset there exists an inverse correlation between $T D G$ expression and DNA methylation levels, which indicates that the role of TDG in intestinal tumor formation may be linked to its function in DNA demethylation, i.e. to maintenance of epigenomic stability.

On the other hand, TDG DNA repair activity may also play a role in intestinal tumor formation, via maintenance of genomic stability of $\mathrm{CpG}$ sites, i.e. the subset of tumors with low TDG expression may exhibit high levels of transition mutations at $\mathrm{CpG}$ sites. However, the fact that the second allele of $A p c$ is inactivated by loss of heterozygosity rather than by point mutations, as is the case for Mbd4 mutant mice [24, 25], argues against this possibility. Be as it may, additional studies are warranted that will more directly examine the mutational impact of reduced TDG activity.

It has been suggested that TDG is a positive regulator of $\mathrm{WNT} / \beta$-catenin signaling in $\mathrm{CRC}[38,41]$. On the other hand, TCGA mutational profiling of CRC revealed the presence of mutations in several WNT pathway genes, often in combination with $A P C$ mutations, indicating that multiple alterations of WNT signaling are needed for CRC formation and may be under positive

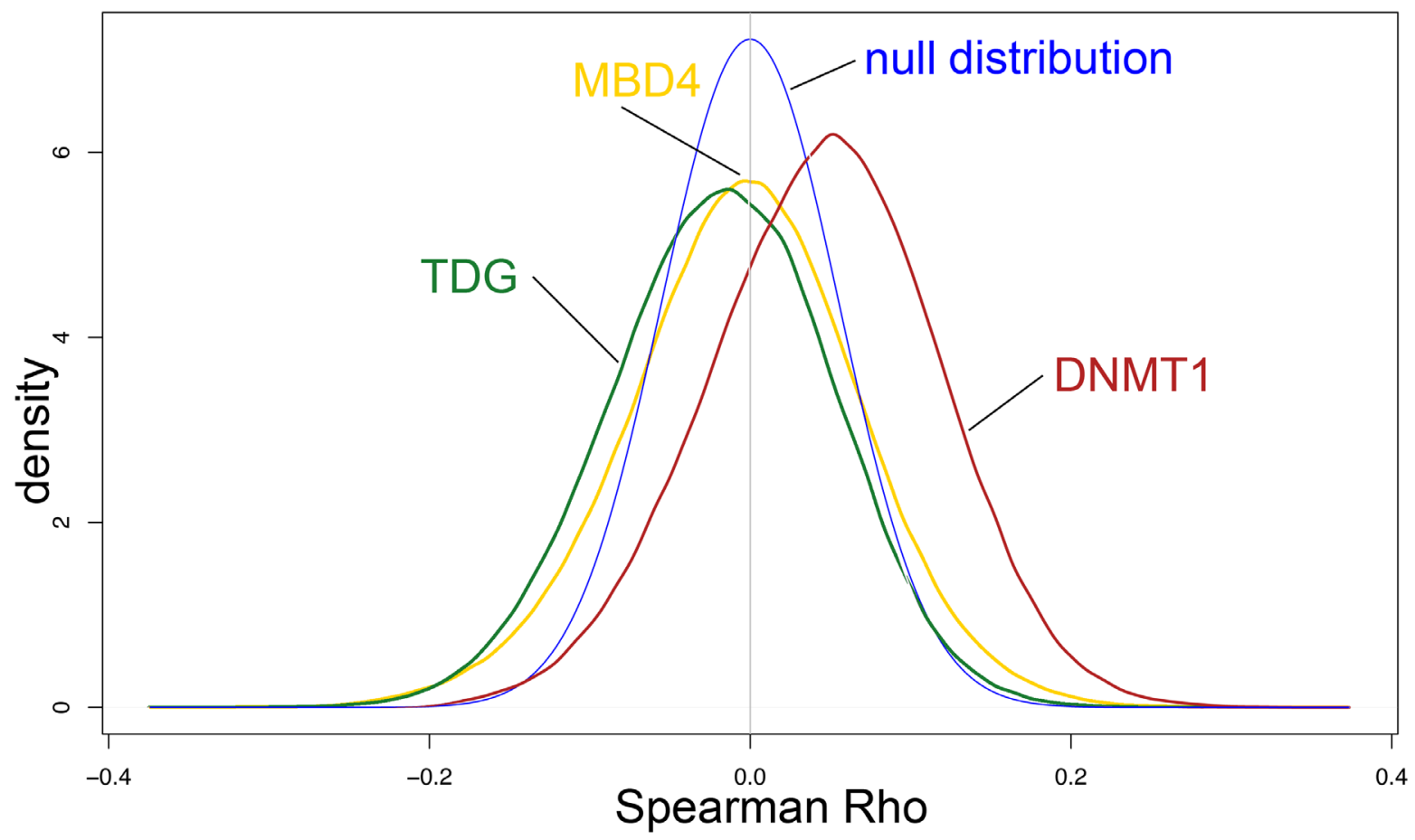

Figure 4: Impact of TDG, MBD4 and DNMT1 expression on epigenome of CRC cases from the TCGA database. Spearman correlations of TDG, MBD4 and DNMT1 expression with Infinium 450K probe beta values. The null distribution is indicated. Methylation levels at more sites are negatively correlated with $T D G$ expression than are positively correlated, thus causing a shift of the plot to the left of the null distribution curve. Conversely, DNMT1 expression correlates positively with methylation levels, thus causing a shift of the plot to the right of the null distribution curve. MBD4 expression did not show any preferential correlation. 
selection [42]. Thus, the CRC subset with low TDG expression levels may impair WNT signaling and promote tumorigenesis in combination with $A P C$ mutation/reduced expression.

In summary, these observations support a role of reduced $T D G$ expression in the pathogenesis of $\mathrm{CRC}$. However, it remains to be determined the significance of TDG in those CRC cases that manifest maintained/ increased TDG expression; these cases may underscore the need for tumor cells to retain or enhance a hitherto unclear function of this gene that in fact may potentially represent a novel vulnerability of cancer.

\section{MATERIALS AND METHODS}

\section{Mice, pathological analysis and histopathology}

Mice bearing the null $T d g$ allele $\left(T d g^{-}\right)$and mice harboring the original $T d g$ recombined locus, that includes the neo ${ }^{\mathrm{R}}$ gene and the loxP and frt recombination sites $\left(T d g^{\text {neoflox }}\right)$, have been previously described (10). Mice expressing the enhanced Flp recombinase at the Rosa26 locus (Rosa26::FlpeR) [29], Fabpl::Cre transgenic mice $[30,31]$, and the Fox Chase Cancer Center strain of the $A p c^{\text {Min }}$ mice, $A p c^{\text {Min-FCCC }}$ [32] have also been described and maintained on a C57/BL6 background.

Initially, mice bearing the conditional Tdg allele $\left(T d g^{\text {flox }}\right)$, generated by crossing $T d g^{\text {neoflox }}$ mice with Rosa26::FlpeR and $T d g^{-}$mice, had a mixed genetic background that was approximately 75\% C57/BL6 and $25 \% 129 / \mathrm{Sv}-J$. Subsequent experiments were conducted after at least 10 backcrosses into C57/BL6, therefore the genetic background of these two strains was approximately 99.8\% C57/BL6 and 0.2\% 129/Sv-J.

Mice were housed in the Fox Chase Cancer Center Laboratory Animal Facility, a fully accredited facility, and all experiments were approved by the Fox Chase Cancer Center Institutional Animal Care and Use Committee.

All the genotyping was conducted by PCR analysis of mouse tail genomic DNA; primer sequences and PCR conditions are available upon request.

Mice were euthanized by $\mathrm{CO}_{2}$ asphyxiation and examined at 150 days. For pathological examination, the small and large intestine were excised, opened with a longitudinal cut and rinsed in phosphate buffer saline. Small and large intestine were examined under a dissecting microscope and gross lesions were counted. For histopathology, the small intestine was analyzed by the "jelly roll" method, a procedure in which the tissue is rolled on a stick before fixation in buffered formalin, paraffin-embedding, sectioning and hematoxylin/eosin staining; whereas the cecum and colorectum were cut in cross sections, in a "bread loaf" fashion, at $2 \mathrm{~mm}$ intervals. Adenomas were verified microscopically using established criteria [43].

\section{Ovariectomy}

Sexually immature female mice (5-6 week old) were anesthetized with isoflurane and ovariectomized bilaterally. A skin incision was made on the dorsal surface of mice to expose and remove the ovaries. After the operation, the mice were kept on a warm platform for 2 hours until their complete recovery.

\section{Analysis of loss of heterozygosity of $A p c$ by pyrosequencing}

A region of the mouse $A p c$ gene around the Min mutation was amplified by polymerase chain reaction using the following primers 5'Bio-CCT CAA GGG GAA GTT TAG ACA GTT-3' and 5'- GAT GGT AAG CAC TGA GGC CAA TA -3'. The 5'-biotinylated forward primer for the pyrosequencing reaction was isolated using streptavidin-coated Sepharose beads (Amersham Biosciences, Piscataway, NJ) and the PSQ 96 Sample Preparation kit (Biotage, Westborough, MA). The singlestrand DNA template was incubated with sequencing primer 5'- CTG AGG CCA AT ACCT CG -3'. The sequencing by synthesis reaction of the complementary strand was performed on a PSQ 96MA instrument (Biotage) using PyroGold reagents (Biotage).

\section{Cell culture and western blot analysis}

The CRC cell lines of the NCI-60 panel were grown in RPMI supplemented with $10 \%$ fetal bovine serum. Western blotting was conducted as previously described (10). Briefly, cells were lysed in RIPA buffer (50 mM Tris $\mathrm{HCl} \mathrm{pH} 7.4,150 \mathrm{mM} \mathrm{NaCl}, 1 \%$ sodium deoxycholate, $1 \%$ Triton X-100, 0.1\% SDS, $10 \mathrm{mM}$ $\mathrm{NaF}, 1 \mathrm{mM}$ each of sodium pyrophosphate, sodium orthovanadate, dithiothreitol, and EDTA), plus protease inhibitors. Lysates were fractionated by SDS-PAGE and transferred to PVDF membranes (Millipore). Membranes were blocked in 4\% nonfat dry milk in PBS and incubated with anti-Tdg antibody (gift of Dr. K. Sugasawa), 1/400 dilution, or anti- $\beta$-actin (Abcam), 1/10,000 dilution, in $2 \%$ nonfat dry milk in PBS. Detection was performed using enhanced chemiluminescence (Amersham).

\section{Statistical analysis}

The two-sided Mann-Whitney test was used to compare the number of adenomas between mutant and control groups. For the box-plots shown in Figures $1 \mathrm{~B}, 3 \mathrm{~F}$, and $3 \mathrm{G}$, the height of the box represents the inter-quartile range (IQR), where the upper and lower ends indicate the third and first quartiles, respectively. The solid black horizontal line inside the box represents the median value while the whiskers (the two solid horizontal lines at either end, connected by dotted lines) extend to 
the most extreme data points which are no more than 1.5 times the IQR from the box in each direction. Using this criterion, the points that lie beyond these whiskers are considered to be outliers.

The Wilcoxon signed-rank test was used to compare gene expression intensities between matched tumor and normal samples, Comparison of overall survival between groups representing levels of TDG expression was performed via Kaplan-Meier analysis; the log-rank test was used to assess significance. Fisher's exact test was used to test association between gender and membership in the low $T D G /$ low $A P C$ group.

A Type I Error of $5 \%$ was used to determine statistical significance.

\section{Bioinformatics analysis}

Level 3 clinical, RNA-seq, and Illumina 450K methylation data for colon adenocarcinoma (COAD) and rectum adenocarcinoma (READ) were downloaded from the TCGA data portal in January, 2016. RSEM gene-level normalized counts and beta-values (ratio of methylated probe intensity to overall intensity for each interrogated site) were used as gene expression values and methylation measurements, respectively.

\section{ACKNOWLEDGMENTS}

We thank Sergei Grivennikov, Alyssa Leystra and Timothy Yen for critical reading of the manuscript; and L. Cathay for secretarial assistance. We thank the following core facilities and personnel at the Fox Chase Cancer Center: Cell Culture (P. Nakajima), Experimental Histopathology (C. Renner and K. Qai), Transgenic (X. Hua), and Laboratory Animal Facility (S. Tarpinian, T. Lerro, A.M. Pimble). This study was supported by NIH grants CA78412 and CA06927, and an appropriation from the Commonwealth of Pennsylvania to the Fox Chase Cancer Center.

\section{CONFLICTS OF INTEREST}

The authors declare no conflicts of interest.

\section{REFERENCES}

1. Lindahl T, Wood RD. Quality control by DNA repair. Science. 1999; 286:1897-1905.

2. Pearl LH, Savva R. The problem with pyrimidines. Nat Struct Biol. 1996; 3:485-487.

3. Jones PA, Rideout WM 3rd, Shen JC, Spruck CH, Tsai YC. Methylation, mutation and cancer. Bioessays. 1992; 14:33-36.
4. Schmutte C, Jones PA. Involvement of DNA methylation in human carcinogenesis. Biol Chem. 1998; 379:377-388.

5. Alexandrov LB, Nik-Zainal S, Wedge DC, Aparicio SA, Behjati S, Biankin AV, Bignell GR, Bolli N, Borg A, Borresen-Dale AL, Boyault S, Burkhardt B, Butler AP, et al. Signatures of mutational processes in human cancer. Nature. 2013; 500:415-421.

6. Cortazar D, Kunz C, Saito Y, Steinacher R, Schar P. The enigmatic thymine DNA glycosylase. DNA Repair (Amst). 2007; 6:489-504.

7. Sjolund AB, Senejani AG, Sweasy JB. MBD4 and TDG: multifaceted DNA glycosylases with ever expanding biological roles. Mutat Res. 2013; 743:12-25.

8. Bellacosa A. Role of MED1 (MBD4) Gene in DNA repair and human cancer. J Cell Physiol. 2001; 187:137-144.

9. Bellacosa A, Drohat AC. Role of base excision repair in maintaining the genetic and epigenetic integrity of $\mathrm{CpG}$ sites. DNA Repair. 2015

10. Cortellino S, Xu J, Sannai M, Moore R, Caretti E, Cigliano A, Le Coz M, Devarajan K, Wessels A, Soprano D, Abramowitz LK, Bartolomei MS, Rambow F, et al. Thymine DNA glycosylase is essential for active DNA demethylation by linked deamination-base excision repair. Cell. 2011; 146:67-79.

11. Dalton SR, Bellacosa A. DNA demethylation by TDG. Epigenomics. 2012; 4:459-467.

12. Schuermann D, Weber AR, Schar P. Active DNA demethylation by DNA repair: Facts and uncertainties. DNA Repair (Amst). 2016; 44:92-102.

13. Cortazar D, Kunz C, Selfridge J, Lettieri T, Saito Y, Macdougall E, Wirz A, Schuermann D, Jacobs AL, Siegrist F, Steinacher R, Jiricny J, Bird A, Schar P. Embryonic lethal phenotype reveals a function of TDG in maintaining epigenetic stability. Nature. 2011; 470:419-423.

14. Baker SJ, Preisinger AC, Jessup JM, Paraskeva C, Markowitz S, Willson JK, Hamilton S, Vogelstein B. p53 gene mutations occur in combination with $17 \mathrm{p}$ allelic deletions as late events in colorectal tumorigenesis. Cancer Res. 1990; 50:7717-7722.

15. Kleihues P, Schauble B, zur Hausen A, Esteve J, Ohgaki H. Tumors associated with $\mathrm{p} 53$ germline mutations: a synopsis of 91 families. Am J Pathol. 1997; 150:1-13.

16. Greenblatt MS, Bennett WP, Hollstein M, Harris CC. Mutations in the p53 tumor suppressor gene: clues to cancer etiology and molecular pathogenesis. Cancer Res. 1994; 54:4855-4878.

17. Helleday T, Eshtad S, Nik-Zainal S. Mechanisms underlying mutational signatures in human cancers. Nat Rev Genet. 2014; 15:585-598.

18. Feinberg AP, Vogelstein B. Hypomethylation distinguishes genes of some human cancers from their normal counterparts. Nature. 1983; 301:89-92.

19. Issa JP. CpG island methylator phenotype in cancer. Nat Rev Cancer. 2004; 4:988-993. 
20. Riccio A, Aaltonen LA, Godwin AK, Loukola A, Percesepe A, Salovaara R, Masciullo V, Genuardi M, ParavatouPetsotas M, Bassi DE, Ruggeri BA, Klein-Szanto AJP, Testa $\mathrm{JR}$, et al. The DNA repair gene MBD4 (MED1) is mutated in human carcinomas with microsatellite instability. Nat Genet. 1999; 23:266-268.

21. Bader S, Walker M, Harrison D. Most microsatellite unstable sporadic colorectal carcinomas carry MBD4 mutations. Br J Cancer. 2000; 83:1646-1649.

22. Evertson S, Wallin A, Arbman G, Rutten S, Emterling A, Zhang H, Sun XF. Microsatellite instability and MBD4 mutation in unselected colorectal cancer. Anticancer Res. 2003; 23:3569-3574.

23. Tricarico R, Cortellino S, Riccio A, Jagmohan-Changur S, Van der Klift H, Wijnen J, Turner D, Ventura A, Rovella V, Percesepe A, Lucci-Cordisco E, Radice P, Bertario L, et al. Involvement of MBD4 inactivation in mismatch repairdeficient tumorigenesis. Oncotarget. 2015; 6:42892-42904. https://doi.org/10.18632/oncotarget.5740.

24. Millar CB, Guy J, Sansom OJ, Selfridge J, MacDougall E, Hendrich B, Keightley PD, Bishop SM, Clarke AR, Bird A. Enhanced $\mathrm{CpG}$ mutability and tumorigenesis in MBD4deficient mice. Science. 2002; 297:403-405.

25. Wong E, Yang K, Kuraguchi M, Werling U, Avdievich E, Fan K, Fazzari M, Jin B, Brown AM, Lipkin M, Edelmann W. Mbd4 inactivation increases $\mathrm{C} \rightarrow \mathrm{T}$ transition mutations and promotes gastrointestinal tumor formation. Proc Natl Acad Sci U S A. 2002; 99:14937-14942.

26. Su LK, Kinzler KW, Vogelstein B, Preisinger AC, Moser AR, Luongo C, Gould KA, Dove WF. Multiple intestinal neoplasia caused by a mutation in the murine homolog of the APC gene. Science. 1992; 256:668-670.

27. Moser AR, Pitot HC, Dove WF. A dominant mutation that predisposes to multiple intestinal neoplasia in the mouse. Science. 1990; 247:322-324.

28. Vasovcak P, Krepelova A, Menigatti M, Puchmajerova A, Skapa P, Augustinakova A, Amann G, Wernstedt A, Jiricny J, Marra G, Wimmer K. Unique mutational profile associated with a loss of TDG expression in the rectal cancer of a patient with a constitutional PMS2 deficiency. DNA Repair. 2012.

29. Farley FW, Soriano P, Steffen LS, Dymecki SM. Widespread recombinase expression using FLPeR (flipper) mice. Genesis. 2000; 28:106-110.

30. Saam JR, Gordon JI. Inducible gene knockouts in the small intestinal and colonic epithelium. J Biol Chem. 1999; 274:38071-38082.

31. Wong MH, Saam JR, Stappenbeck TS, Rexer CH, Gordon JI. Genetic mosaic analysis based on Cre recombinase and navigated laser capture microdissection. Proc Natl Acad Sci U S A. 2000; 97:12601-12606.

32. Cooper HS, Chang WC, Coudry R, Gary MA, Everley L, Spittle CS, Wang H, Litwin S, Clapper ML. Generation of a unique strain of multiple intestinal neoplasia $(\mathrm{Apc}(+/$ Min-FCCC)) mice with significantly increased numbers of colorectal adenomas. Mol Carcinog. 2005; 44:31-41.

33. Luongo C, Moser AR, Gledhill S, Dove WF. Loss of Apc+ in intestinal adenomas from Min mice. Cancer Res. 1994; 54:5947-5952.

34. Chen D, Lucey MJ, Phoenix F, Lopez-Garcia J, Hart SM, Losson R, Buluwela L, Coombes RC, Chambon P, Schar P, Ali S. T:G mismatch-specific thymine-DNA glycosylase potentiates transcription of estrogen-regulated genes through direct interaction with estrogen receptor alpha. J Biol Chem. 2003; 278:38586-38592.

35. Liu Y, Duong W, Krawczyk C, Bretschneider N, Borbely G, Varshney M, Zinser C, Schar P, Ruegg J. Oestrogen receptor beta regulates epigenetic patterns at specific genomic loci through interaction with thymine DNA glycosylase. Epigenetics \& chromatin. 2016; 9:7.

36. Weyant MJ, Carothers AM, Mahmoud NN, Bradlow HL, Remotti H, Bilinski RT, Bertagnolli MM. Reciprocal expression of ERalpha and ERbeta is associated with estrogen-mediated modulation of intestinal tumorigenesis. Cancer Res. 2001; 61:2547-2551.

37. Grodstein F, Newcomb PA, Stampfer MJ. Postmenopausal hormone therapy and the risk of colorectal cancer: a review and meta-analysis. Am J Med. 1999; 106:574-582.

38. Xu X, Yu T, Shi J, Chen X, Zhang W, Lin T, Liu Z, Wang Y, Zeng Z, Wang C, Li M, Liu C. Thymine DNA glycosylase is a positive regulator of Wnt signaling in colorectal cancer. J Biol Chem. 2014; 28:8881-8890.

39. Cho NL, Javid SH, Carothers AM, Redston M, Bertagnolli MM. Estrogen receptors alpha and beta are inhibitory modifiers of Apc-dependent tumorigenesis in the proximal colon of Min/+ mice. Cancer Res. 2007; 67:2366-2372.

40. Hasson RM, Briggs A, Carothers AM, Davids JS, Wang J, Javid SH, Cho NL, Bertagnolli MM. Estrogen receptor alpha or beta loss in the colon of Min/+ mice promotes crypt expansion and impairs TGFbeta and HNF3beta signaling. Carcinogenesis. 2014; 35:96-102.

41. Jia Y, Nie F, Du A, Chen Z, Qin Y, Huang T, Song X, Li L. Thymine DNA glycosylase promotes transactivation of beta-catenin/TCFs by cooperating with CBP. J Mol Cell Biol. 2014; 6:231-239.

42. Cancer Genome Atlas Network. Comprehensive molecular characterization of human colon and rectal cancer. Nature. 2012; 487:330-337.

43. Boivin GP, Washington K, Yang K, Ward JM, Pretlow TP, Russell R, Besselsen DG, Godfrey VL, Doetschman T, Dove WF, Pitot HC, Halberg RB, Itzkowitz SH, et al. Pathology of mouse models of intestinal cancer: consensus report and recommendations. Gastroenterology. 2003; 124:762-777. 